DOI: $10.5007 / 2175-8085.2011 \mathrm{v} 14 \mathrm{n} 1 \mathrm{p} 51$

\title{
O ENFOQUE HISTÓRICO-ESTRUTURAL E A CRÍTICA RELEGADA ${ }^{1}$
}

\author{
Fábio Pádua dos Santos
}

\section{Resumo}

O presente texto procura: por um lado, realizar uma revisão do pensamento originário da Cepal, privilegiando os aspectos constitutivos do modo de pensamento cepalino e de suas implicações para a formulação de narrativas históricas sobre a formação e desenvolvimento das economias latino-americanas; por outro, argumenta que a Perspectiva dos Sistemas-Mundo pode contribuir, a partir de sua critica epistemológica, para a revisão crítica dos modelos explicativos da formação e desenvolvimento das economias latino-americanas.

Palavras-chave: Cepal, Sistema-Mundo, América Latina.

Classificação JEL: N01; O54.

"Reconhecer e estudar tradições, um difícil desafio. Não significa reconciliarse com elas. Mas simplesmente uma condição essencial para compreendê-las e compreender a nós mesmos, seus herdeiros. E pode significar também, se as circunstâncias permitirem, e se o âmbito ajudar, alcançar o melhor ponto de vista para contribuir no sentido de sua superação".

Daniel Arão Reis Filho

\section{INTRODUÇÃO}

O presente texto procura realizar um estudo do pensamento originário da Cepal, privilegiando os aspectos constitutivos do modo de pensamento ${ }^{3}$

\footnotetext{
Versão modificada do ensaio Estruturalismo latino-americano e a Perspectiva dos Sistemas-Mundo: notas sobre o modo e pensamento da Cepal escrito pela ocasião do IV Colóquio Brasileiro em Economia Política dos Sistemas-Mundo realizado na cidade de Florianópolis em agosto de 2010. O autor agradece aos professores Pedro Antonio Vieira e Eduardo Barros Mariutti, bem como à Fernando Correa Prado, Eduardo Martins Ráo, Leonardo Dias Nunes e à Maíra Machado Bichir pelas críticas e sugestões. As opiniões aqui defendidas são de responsabilidade exclusiva do autor. Mestrando do Programa de Pós-Graduação em Desenvolvimento Econômico do Instituto de Economia da Universidade Estadual de Campinas. Área de concentração: história econômica. Bolsista do Centro Internacional Celso Furtado. E-mail: fpadua@gmail.com

3 Por modo de pensamento entende-se a maneira como os homens realmente pensam. Nestes termos, entretanto não exclusivamente, parte-se da problemática tal como proposta por Karl Mannheim para quem o pensamento deve ser
} 
cepalino e suas implicações para a formulação de narrativas históricas sobre a formação e desenvolvimento das economias latino-americanas.

$\mathrm{O}$ retorno às primeiras formulações da Cepal se justifica em virtude da maneira como vem se delineado o debate sobre o desenvolvimento na última década. As tentativas de interpretação de nosso próprio tempo, ao que parece, têm resgatado problemáticas e expectativas do passado sem antes repensarem profundamente os modelos explicativos em conseqüência das mudanças sociais em curso. Precisamente, os esforços correntes não têm redefinido radicalmente os parâmetros dentro dos quais o fenômeno do desenvolvimento é estudado. Entendemos que a época histórica pelo qual passamos, a Crise da Modernidade 4 , exige, por um momento, centrar atenção no modo como foram elaborados os modelos explicativos da formação e do desenvolvimento das economias latino-americana nos diferentes momentos do capitalismo histórico. A necessidade deste tipo de revisão se coloca em razão das transformações de longa duração que se vêm processando no sistema-mundo moderno ${ }^{5}$ e que têm colocado em dúvida, no debate recente sobre o desenvolvimento, a validade de modelos explicativos outrora forjados e que continuam sendo a base do debate mais recente.

É claro que este retorno à Cepal não se constitui em um fim em si, senão um meio para o exercício crítico de nossa contemporaneidade. O trabalho de revisar as diferentes interpretações da formação e desenvolvimento das economias latino-americanas requer um minucioso balanço historiográfico das principais visões que se constituíram em torno do debate sobre o desenvolvimento ao longo da segunda metade do século XX. Este trabalho

compreendido “... dentro da moldura concreta de uma situação histórico-social, de que o pensamento individualmente diferenciado emerge mui gradualmente. Assim não são os homens em geral que pensam, nem mesmo os indivíduos isolados, mas os homens dentro de certos grupos que elaboram um estilo peculiar de pensamento graças a uma série interminável de reações a certa situações típicas, características de sua posição comum". MANNHEIM, Karl. Ideologia

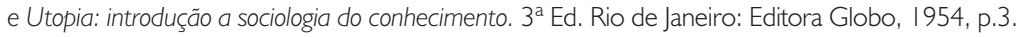

4 Por Crise da Modernidade se está entendendo as diferentes dimensões da crise estrutural. Ela é, ao mesmo tempo: econômica, pelo fato de estarmos chegando muito próximo da mercantilização de tudo; política, pelo fato dos próprios movimentos anti-sistêmicos estarem em crise; e cultura, pelo fato dos estudos da complexidade estarem colocando em dúvida as premissas da ideologia universalista. Para mais detalhes ver WALLERSTEIN (1985, pp.77-80).

5 Vide: WALLERSTEIN, Immanuel. "La crisis como transición" In: AMIM, Samir et.al. Dinámica de la Crisis Global., pp. 14-60. Ver também "Structural Crises" In: New Left Review, 62, mar-apr, 20 I0, pp. I33-142. De modo análogo, porém com discordâncias, vide: MÉSZÁROS, István. A crise estrutural do capital. São Paulo: Boitempo, 2009. Ou ainda, para uma introdução ao do debate, ver: CHESNAIS, François. "Um momento histórico crítico"; FIORI, José Luís. "A esquerda e a crise; BRENNER, Robert. "A crise que se aprodunda"; e GOWAN, Peter. "Crises na capital". In: Margem Esquerda - ensaios marxistas. No. 13. São Paulo: Boitempo Editorial, maio de 2009. 
representa parte desse esforço de balanço.

Nas páginas que seguem, dedica-se especial atenção à primeira fase da Cepal, período no qual foram lançadas as bases para a formulação de um modo de pensamento crítico às estruturas do saber do sistema-mundo moderno. Contudo, este modo peculiar de pensar o fenômeno do desenvolvimento, ao propor uma modalidade de pensamento por essência interdisciplinar sem todavia avançar na crítica epistemológica das ciências sociais, não conseguiu romper com o modo de conceber e interpretar a realidade social do ponto de vista da Economia Política Clássica. Na segunda parte do trabalho, argumenta-se brevemente que a Perspectiva dos Sistemas-Mundo pode se constituir em um plano de trabalho para a revisão crítica dos modelos explicativos da formação e desenvolvimento das economias latino-americanas, pois, esta, ao enfrentar as questões epistemológicas que se apresentam à reflexão das transformações sociais no mundo moderno, lançou mão de um sistema conceitual capaz de transcender as modalidades de pensamento social estruturadas a partir do século XIX.

Para dar conta dessa discussão o ensaio está divido, além desta introdução, em outras duas seções. Na seção II, denominada "notas sobre o modo de pensamento cepalino" procuro descrever sistematicamente o enfoque histórico-estrutural: sua origem, seu significado histórico, as noções fundamentais, o papel da História no esquema analítico cepalino, o encadeamento lógico no processo reflexivo, a ausência de uma crítica epistemológica, além de dar um exemplo de narrativa histórica. Na seção III, busca-se apenas indicar como a Perspectiva dos Sistemas-Mundo pode contribuir para a compreensão da realidade latino-americana. Seguem-se as considerações finais.

\section{NOTAS SOBRE O MODO DE PENSAMENTO CEPALINO}

\section{O "manifesto dos subdesenvolvidos"}

Karl Marx escreveu que "do mesmo modo que não se julga o indivíduo pela idéia que de si mesmo faz, tampouco se pode julgar uma tal época de transformações pela consciência que ela tem de si mesma" ". Para compre-

\footnotetext{
Comentário de Albert Hirschman sobre o texto clássico de Raúl Prebisch El desarrollo económico de la América Latina y algunos de sus principales problemas.

MARX, Karl. Contribuição à crítica da Economia Política. 2a Ed. São Paulo: Expressão Popular, 2008 [1859], p.48.
} 
endermos o significado histórico do pensamento cepalino em sua totalidade seria preciso reconstruir sua época, as exigências que nela via a CEPAL, bem como o horizonte de expectativa contido em tal pensamento. Embora este trabalho precise ser feito com atenção e minúcia, nos limites do presente texto considera-se suficiente expor apenas algumas opiniões acerca do que significou a CEPAL na ocasião de sua formação e da divulgação dos seus primeiros informes - noutras palavras, como aquele momento foi posteriormente percebido e compreendido por outros autores.

Em meados da década de 1970, João Manuel Cardoso de Mello, ao se reportar ao Estudio de América Latina de 1949, reconhecera neste documento "o nascimento da Economia Política da CEPAL". ${ }^{8}$ Octavio Rodríguez, alguns anos depois, em 1980 e comprometido com a instituição, assinalou que o Estudio de 1949, num sentido mais amplo, delineará as idéias-chave que vieram fundar uma tradição no pensamento latino-americano, ${ }^{9}$ que mais tarde Rodríguez veio a denominar de Estruturalismo latino-americano. ${ }^{10} \mathrm{Em} 1994$, Ruy Mauro Marini sugeria que a CEPAL, por um lado, compusera no essencial "una agencia de difusión de la teoría del desarrollo que se planteara en Estados Unidos y Europa, al término de la segunda guerra mundial" 11 com o propósito de "responder a la inquietud y la inconformidad manifestadas por las nuevas naciones (...) al darse cuenta de las enormes desigualdades que caracterizaban a las relaciones económicas internacionales"12. Por outro, embora ela partisse da Teoria do Desenvolvimento - avaliada por Marini como "política de domesticação ideológica contra as pressões que vinham do Terceiro Mundo" - a CEPAL não se limitou à mera difusão de tal ideologia. Para Marini, esta instituição "asume el papel de verdadera creadora de ideologias, una vez que se trata de captar y explicar las especificidades de América Latina"13 e se distinguiu das diferentes agencias similares naquela época por ter sido "instrumentalizada por la burguesia

8 Mello, João Manuel Cardoso de. O Capitalismo Tardio: contribuição à revisão crítica da formação e do desenvolvimento da economia brasileira. $3^{a}$ Ed. São Paulo: Brasiliense, 1984 [tese de doutorado defendida em 1975 na Universidade Estadual de Campinas], p. 13.

9 RODRÍGUEZ, Octavio. La teoría del subdesarrollo de la CEPAL. México, Siglo XXI Editores, 1980.

${ }^{10}$ A questão da unidade do pensamento latino-americano e colocada em seu trabalho mais recente RODRÍGUEZ, Octavio. El estructuralismo latinoamercano. México, Siglo XXI Editores : Cepal, 2006.

MARINI, Ruy Mauro. La crisis del desarrollismo. Arquivo de Ruy Mauro Marini, com a anotação "( 1994 )". Disponível em: < < http://www.marini-escritos.unam.mx/026_crisis_desarrollismo_es.htm $>>$.

12 MARINI R.M, ibid., 1994.

13 MARINI R.M, ibid., 1994. 
industrial, tanto en función de lucha sociales y políticas internas, como de los conflictos estabelecidos a nivel de la economía mundial" ${ }^{14}$. Foi nesta distinção, pois, que residiu, do ponto de vista da teoría do conhecimento, a contribuição cepalina ao pensamento econômico: "ello hará con que la Cepal" afirmou Marini, "partiendo de la teoría del desarrollo, en los términos en que había sido formulada en los grandes centros introduzca en ella cambios que representarán su contribución propia, original, y que harán del desarrollismo latinoamericano un producto sí, pero no un simple calco de la teoría del desarrollo" "15. Já Ricardo Bielschowsky caracterizara, no final da década de 1990, a partir das noções de história do pensamento econômico delineadas por Joseph A. Schumpeter, que o Estudio de 1949 também representou o nascimento de um "sistema de economia política" latino-americano, cujo "princípio 'normativo' é a idéia da necessidade da contribuição do Estado ao ordenamento do desenvolvimento econômico nas condições da periferia latino-americana". ${ }^{16}$ Segundo Bielschowsky, o surgimento do sistema de economia política latino-americano sucedeu ao reconhecimento por parte de seus fundadores de "um certo descompasso entre a história econômica e social e a construção de sua contrapartida no plano ideológico e analítico"17. Contemporâneo à resenha de Bielschowsky, Ramón Grosfoguel, ao resgatar a contribuição de Raúl Prebisch a partir do dilema metodológico idiográfico-nomotético, reconhecera que Prebisch "was the first economist from peripheral zone to elaborate a theorical and conceptual framework challenging the nomothetic doctrines of the core's classical economic theories" ${ }^{18}$ Immanuel Wallerstein, por sua vez, interpretara o esforço cepalino de teorização de maneira muito instigante. Para Wallerstein, o "manifesto dos subdesenvolvidos" era o reflexo no Terceiro Mundo da incerteza cada vez maior a respeito das verdades tradicionais consolidadas no século XIX e que foram abaladas pelas transformações pelas quais o mundo passou entre 1914 e $1945 .{ }^{19}$

Nessas diferentes apreciações do Estudio Económico de América Lati-

\footnotetext{
4 MARINI R.M, ibid., 1994.

15 MARINI R.M, ibid., 1994 negrito nosso.

${ }^{6}$ BIELSCHOWSKY, Ricardo. Cinqüenta Anos de Pensamento da CEPAL - Uma Resenha. In: Bielschowsky, R. Cinqüenta anos de pensamento na Cepal. Vol. I Rio de Janeiro: Record, 1998. p.I6.

7 BIELSCHOWSKY, R. ibid., I998, p.24.

18 GROSFOGUEL, Ramón. A TimeSpace Perspective on Development: recasting Latin America Debates. In: Review, XX, 3/4, Summer/Fall, 1997, p.483.

19 WALLERSTEIN, Immanuel. World-System Analysis: an introduction. Durham: Duke University Press, 2004, p. I I- 12
} 
$n a-1949$, podemos observar as distintas formas - e conseqüentemente as diferentes dimensões - nas quais o pensamento cepalino foi estudado e, principalmente, os significados diversos que tal pensamento adquiriu de acordo com a forma com a qual ele foi compreendido nos diferentes momentos em que ele foi recuperado. Seja para apontar os limites analíticos do método de investigação cepalino, seja para assinar a ideologia subjacente a este pensamento, seja para identificar uma tradição, ou ainda, para realçar o impacto do pensamento cepalino nas estruturas do saber da economia-mundo capitalista, é fato que a maneira através da qual os cepalinos problematizaram o fenômeno do desenvolvimento e como este "estilo" foi justificado, constituiu um modo peculiar de pensar. Este modo de pensamento - que além do sistema de valores morais (concepção de mundo) dos quais seus propositores compartilhavam constituiu-se, sobretudo, num conjunto de procedimentos "sistemáticos" para interpretação da realidade latino-americana - que, com o passar do tempo, recebeu a denominação de enfoque histórico-estrutural.

Centrar a análise no enfoque histórico-estrutural pode constituir um bom ponto de partida para explorar as diferenças apresentadas pelas distintas correntes de pensamento social latino-americano na interpretação da realidade latino-americana e também como a Cepal e correntes que dela derivaram podem ser revisitadas tendo em mente as transformações contemporâneas à luz da Perspectiva dos Sistemas-Mundo. Uma vez que a realidade histórico-concreta está dada, as diferentes compreensões que puderam ser alcançadas sobre épocas determinadas residem antes no modo de apreensão destas determinadas realidades e na forma como estas modalidades de pensamento foram ensejadas, por um lado, e restringidas por sua própria época, por outro.

\section{O enfoque histórico-estrutural como modo de pensamento}

A Economia Política de David Ricardo, sobretudo sua interpretação a respeito do comércio internacional, é o reflexo científico do princípio que orientou as reflexões acerca das relações econômicas internacionais, pelo menos até a Crise de Hegemonia britânica. De acordo com esta doutrina não haveria espaço para a industrialização dos países que emergiram da Crise do Antigo Sistema Colonial, uma vez que a especialização produtiva que havia sido forjada no período colonial beneficiaria a todos os países conectados à divisão internacional do trabalho. Contudo, "los hechos la están imponiendo, 
sin embargo", afirmou Raúl Prebisch, referindo à industrialização na América Latina, no clássico texto El desarrollo económico de América Latina y algunos de sus principales problemas. Naquela época, em 1949, os fatos já demonstravam que a atividade industrial era possível nos países periféricos. A realidade latino-americana estava contestando, pois, o argumento da Economia Política Clássica. Vejamos como Raúl Prebisch percebeu esta questão:

\begin{abstract}
Es cierto que el razonamiento acerca de las ventajas económicas de la división internacional del trabajo es de una validez teórica inobjetable. Pero suele olvidarse que se basa sobre una premisa terminantemente contradicha por los hechos. Según esta premisa, el fruto del progreso técnico tiende a repartirse parejamente entre toda la colectividad, ya sea por la baja de los precios o por el alza equivalente de los ingresos. Mediante el intercambio internacional, los países de producción primaria obtienen su parte en aquel fruto. No necesitan, pues, industrializarse. Antes bien, su menor eficiencia les haría perder irremisiblemente las ventajas clásicas del intercambio. ${ }^{20}$
\end{abstract}

Fica claro nesta citação que para Prebisch não é o comércio internacional em si que se constitui numa premissa teórica falsa. Para ele o equivoco está em considerar que a troca internacional tende a repartir equitativamente entre todas as sociedades os frutos do progresso técnico.

A sagacidade de Prebisch está em chamar a atenção para a não correspondência entre a doutrina econômica evocada a partir do centro e a realidade observada na periferia. Segundo ele, "la falla de esta premisa consiste en atribuir carácter general a lo que de suyo es muy circunscrito" 21. Tal consciencia foi alcançada da constatação de que "las ingentes ventajas no han llegado a la periferia en medida comparable a la que ha logrado disfrutar la población de esos grandes países"22.

Em 1949, se por um lado, os fatos já haviam dado provas suficientes que os benefícios do progresso técnico não eram distribuídos equitativamente pelo sistema de trocas internacionais, e por outro, que havia lugar para a industrialização nos países periféricos, Prebisch não hesitou em sugerir a

\footnotetext{
20 PREBISCH, Raúl. El desarrollo económico de América Latina y algunos de sus principales problemas. In: Desarrollo Económico, Vol. 26, No. 103. (Oct. - Dec., 1986), pp. 479-502. [1949], p.479.

21 PREBISCH, R. ibid., 1986, p.479.

22 PREBISCH, R. ibid., 1986, p.479
} 
industrialização como “... el único medio de que disponen [los países novos] para ir captando uma parte del fruto del progreso técnico y elevando progressivamente el nível de vida de las masas"23.

Não cabe aqui, porém, resenhar toda a exposição e argumentação de Raúl Prebisch. Cabe apenas salientar que a conjuntura histórica colocou à prova o modo de desenvolvimento das economias latino-americanas que vigorava até então, bem como a doutrina que o explicava e o justificava. Não só Prebisch, como também os demais cepalinos, reconheceram nos fatos o significado que a industrialização poderia ter para os países da periferia. Num esforço coletivo, com o fito de elaborar uma teoria latino-americana do desenvolvimento capaz de orientar e estimular o processo de industrialização na região, eles passaram então a sistematizar uma reflexão que partisse da própria realidade latino-americana.

O esforço de crítica à teoria convencional do desenvolvimento e o empenho para desenvolver uma teoria do subdesenvolvimento latino-americano com capacidade efetiva de intervenção na realidade levou Raúl Prebisch a adotar, no princípio, a seguinte atitude diante da temática: esboçar os principais problemas do modo como se desenvolvia a América Latina, com uma perspectiva de conjunto vis-à-vis a reflexões gerais induzidas da observação sistemática da própria vida econômica latino-americana ${ }^{24}$.

Entretanto, a tarefa de pensar o subdesenvolvimento latino-americano encontrava dificuldades de diferentes tipos. Em nota de roda pé, Prebisch aponta algumas das dificuldades que estavam colocadas naquele momento.

Son bien conocidas las dificultades que se oponen en Latinoamérica a una tarea de esta naturaleza. Acaso la principal de ellas sea el número exiguo de economistas capaces de penetrar con criterio original en los fenómenos concretos latinoamericanos. Por una serie de razones, no se logra suplir su carencia con la formación metódica de un número adecuado de hombres jóvenes de alta calificación intelectual. El enviarlos a las grandes universidades de Europa u Estados Unidos representa ya un progreso considerable, pero no suficiente. Pues una de las fallas más conspicuas de que adolece la teoría económica general, contemplada desde la

${ }^{23}$ PREBISCH, R. ibid., 1986, p.479.

24 PREBISCH, R. ibid., 1986, p.479. 
O enfoque histórico-estrutural e a crítica relegada

periferia, es su falso sentido de universalidad.

Mal podría pretenderse, en verdad, que los economistas de los grandes países, embargados en muy serios problemas propios, vayan a dedicar preferentemente su atención al estudio de los nuestros. Concierne primordialmente a los propios economistas latino-americanos el conocimiento de la realidad económica de América Latina. Sólo si se llega a explicarla racionalmente y con objetividad científica será dado alcanzar fórmulas eficaces de acción práctica.

No se interprete, sin embargo, que este propósito está animado de un particularismo excluyente. Por el contrario, sólo se sabrá cumplirlo mediante un sólido conocimiento de las teorías elaboradas en los grandes países, con su gran caudal de verdades comunes. No hay que confundir el conocimiento reflexivo de lo ajeno con una sujeción mental a las ideas ajenas, de la que muy lentamente estamos aprendiendo a librarnos. ${ }^{25}$

Desta citação depreendem-se três pontos: o falso sentido de universalidade do pensamento econômico em geral, o compromisso do economista latino-americano com sua própria realidade e o não relativismo metodológico. Mais adiante será dedicada atenção ao primeiro e ao terceiro ponto. Antes, cabe apresentar o momento pré-analítico da reflexão cepalina que orientou, na sua primeira fase, o esforço de teorização do subdesenvolvimento.

\section{Noções fundamentais do enfoque histórico-estrutural}

A tarefa de pensar o subdesenvolvimento latino-americano, nos moldes propostos pela Cepal, exigia, por um lado, a leitura crítica da produção teórica sobre a temática do desenvolvimento nas diferentes correntes de pensamento em voga para não incorrer num particularismo excludente e, por outro, aprofundar o conhecimento empírico da realidade latino-americana, aprendendo com ela. Tinha-se muito claro que só assim seria possível ensaiar uma interpretação do subdesenvolvimento latino-americano capaz de instrumentalizar decisões práticas com o objetivo de sua superação.

Se a revisão crítica das diferentes correntes do pensamento econômico (clássica, marxista, neoclássica e keynesiana) levou os autores cepalinos a repensarem o caráter universal das proposições teóricas, i.e., do conhecimento;

${ }^{25}$ PREBISCH, R. ibid., 1986, p.482, negrito nosso. 
o estudo da História os levou a reconhecer e conceber "[...] el subdesarrollo como parte del proceso histórico global de desarrollo; tanto el subdesarrollo como el desarrollo son dos aspectos de un mismo fenómeno..."26

Já estava posto àquela época que não havia, pois, como pensar o subdesenvolvimento sem esforço analítico totalizador. Era indispensável partir de uma perspectiva analítica integradora, tanto do ponto de vista dos diferentes aspectos da realidade e das distintas realidades sociais latino-americanas, como também das diferentes disciplinas das ciências sociais. Para tanto, três conceitos edificaram a perspectiva cepalina: sistema, estrutura e processo.

Osvaldo Sunkel e Pedro Paz expuseram de forma precisa cada um destes conceitos.

\section{“...cada estructura es un conjunto de elementos u objetos relacionados entre si también por ciertas leyes (por ejemplo, la estructura económica será el resultado de la forma en que articulan los recursos naturales, el capital, la mano de obra, la tecnología, los mecanismos de financiamiento, etc.)". ${ }^{27}$}

Embora fosse tomada como base, esta noção de estrutura não se limita à estrutura econômica. $\mathrm{O}$ mesmo tipo de raciocínio era replicado implicitamente às estruturas sociais, políticas, etc. De tal modo que,

$$
\begin{aligned}
& \text { en general, un conjunto de estructuras vinculadas entre sí } \\
& \text { por ciertas leyes de funcionamiento (estructura económica, } \\
& \text { social, politica, cultural, etc.), configuran un sistema, en este } \\
& \text { caso, subdesarrollado. }{ }^{28}
\end{aligned}
$$

A noção totalizante a partir da qual a Cepal organizou seu pensamento permitiu conceber o desenvolvimento nem como crescimento, nem como etapa. Ao contrário, reconhecia a simultaneidade histórica do desenvolvimento e do subdesenvolvimento, de forma que estes poderiam ser pensados como "... estructuras parciales pero interdependientes, que componen un sistema único". ${ }^{29}$

É, pois, na forma como as diferentes estruturas se vinculam e se articulam

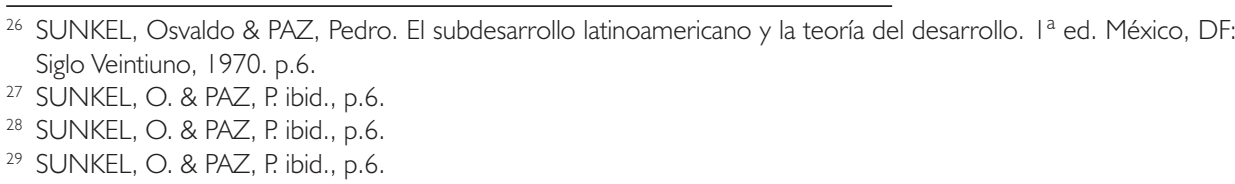


através do tempo que reside a noção de processo e, portanto, de dinâmica:

En consecuencia, el funcionamiento de un sistema estará determinado por la manera como se combinan las estructuras según sus leyes de funcionamiento, o sea, según las formas de vinculación y interacción de las diferentes estructuras. Ese sistema se modifica por efecto de influencias externas significativas que generan cambios en la estructura económica (por ejemplo, estabelecimiento de un sector especializado de exportación), en la estructura social (formación de nuevos grupos sociales), en la estructura política (nuevas formas de participación y organización institucional, etc.). Los cambios que surgen en las distintas estructuras van creando nuevas formas de vinculación entre ellas y palatinas modificaciones, lo que se traducirá en la nueva manera de funcionar del sistema $y$, por consiguiente, en otros resultados. ${ }^{30}$

Se os conceitos sistema, estrutura e processo, na forma como definidos pelo pensamento cepalino podem ou não ser tomados como ponto de partida válido para refletir o fenômeno do desenvolvimento, é uma questão que por hora não se cabe enveredar. Destaca-se apenas o que parece ser mais significativo neste ato pré-analítico: a maneira segundo a qual estes conceitos foram definidos e articulados permitiu postular o desenvolvimento e o subdesenvolvimento como situações de um mesmo processo global de desenvolvimento. Neste quadro analítico, o desenvolvimento passava a significar, portanto, um processo de transformação estrutural. Como bem exprimiram Sunkel e Paz,

Un esquema analítico adecuado para el estudio del desarrollo $y$ del subdesarrollo debe reposar por consiguiente, sobre las nociones de proceso, de estructura, y de sistema. (...) se postula basándose sobre la observación histórica sistemática, que el subdesarrollo es parte del proceso histórico global de desarrollo, que tanto el subdesarrollo como del desarrollo son dos caras de un mismo proceso histórico universal; que ambos procesos son históricamente simultáneos; que están vinculados funcionalmente, es decir, que interactúan y se condicionan mutuamente y que su expresión geográfica concreta se observa en dos grandes dualismos: por una parte, la división

${ }_{30}$ SUNKEL, O. \& PAZ, P. ibid., p.6-7. 
del mundo entre estados nacionales industriales, avanzados, desarrollados, 'centros', y los estados nacionales subdesarrollados, atrasados, pobres, periféricos, dependientes; y por otra, la división dentro de los estados nacional en áreas, grupos sociales y actividades avanzadas y modernas y en áreas, grupos y actividades atrasadas, primitivas y dependientes. ${ }^{31}$

Cabe aqui assinalar que nesse "sistema único" cepalino a diferença fundamental entre a estrutura (parcial) desenvolvida e a estrutura (parcial) subdesenvolvida reside, do ponto de vista econômico, na capacidade endógena de crescimento da primeira, em contraposição ao caráter induzido da dinâmica da acumulação da estrutura dependente, subdesenvolvida, da segunda. Ainda assim, do ponto de vista teórico mais geral, o enfoque histórico-estrutural também admite a possibilidade de pensar o processo de desenvolvimento latino-americano como resultado das tensões entre estruturas - não só econômicas, mas também sociais, políticas e culturais - externas e internas. Precisamente, o processo é resultado da

"...consecuencia de las influencias externas, de las características de las estructuras internas y de las nuevas formas de funcionar del sistema. Este conjunto de elementos estructurales de tipo interno y la naturaleza de sus vinculaciones con el exterior, definen la estructura global de un sistema desarrollado y, en consecuencia, constituyen el marco de referencia dentro del cual se manifiesta el subdesarrollo y su proceso de transformación estructural" (p.7)

Em síntese, entre os elementos essenciais que compõem o enfoque histórico-estrutural, estão as noções de sistema, estrutura e processo. Sistema e estrutura são dois conceitos edificantes na medida em que são sincrônicos (estáticos) e estão presentes em todo o momento da análise, tanto para estudar o passado como para interpretar o presente e planejar o futuro. A noção de processo sintetiza o conteúdo diacrônico (dinâmico) da análise. O processo é a observação de transformações qualitativas da forma como estão vinculados os elementos estruturais (estáticos) que, em geral, são reconhecidos/observados a partir da comparação de distintos momentos no

31 SUNKEL, O. \& PAZ, P. op.cit., 1970, p.37. 
tempo. O caráter "sistêmico" da análise implica que a mudança não deve ser concebida unilateralmente, ao contrário, advém da tensão permanente entre estruturas internas e externas entre países e dentro de países.

Retomando agora o final da seção anterior (seção b) e tendo em mente as noções fundamentais do enfoque histórico-estrutural, pode-se observar que embora a noção centro-periferia pareça simples (países desenvolvidos e países subdesenvolvidos) e de fácil compreensão (industrializados versus primário-exportadores), ela é muito sofisticada e cheia de nuanças. Envolveu, pois, transformar os modos de apreender o desenvolvimento econômico até então convencionais na história do pensamento econômico, em especial aqueles que sem baseavam em explicações universais do processo de desenvolvimento econômico. A noção centro-periferia, portanto, é mais que uma simples percepção sensível das diferentes formas em que se dá o fenômeno do desenvolvimento. Trata-se, pois, de conceitos que emanam da observação empírica e refletem a natureza desigual do desenvolvimento do ponto de vista interno dos diferentes modos de desenvolver-se. É nisto, pois, que se constitui o significado do processo global de desenvolvimento. A noção centro-periferia é o reconhecimento explícito de que não há como pensar o desenvolvimento de estruturas particulares sem considerar o desenvolvimento de outras estruturas, sem levar em conta como estruturas particulares estão vinculadas entre si ou, dito de outro modo, sem privilegiar as relações entre elas. Enfim, a noção centro-periferia não foi só um esforço heurístico de uma situação particular de desenvolvimento econômico. Foi antes um protesto contra o saber econômico tributário de um certo universalismo.

\section{História econômica como historização das leis econômicas}

Até aqui buscou-se apresentar em que consiste e como se articulam os elementos que estruturam o modo de pensamento cepalino. Agora pretende-se completar a exposição do enfoque cepalino discutindo o elemento histórico na reflexão cepalina.

É muito comum se atribuir a alguns cepalinos a produção de clássicos da historiografia econômica latino-americana. Entre os trabalhos de maior evidência, destacam-se: Chile, un caso de Desarrollo Frustrado, publicado em 1956 e de autoria de Aníbal Pinto; Formação Econômica do Brasil, publicado em 1959 por Celso Furtado; ainda deste mesmo autor, A economia 
latino-americana publicado em 1969; La economía argentina de Aldo Ferrer; publicado em 1962; Un ensayo de interpretación del desarrollo latinoamericano, publicado em 1970 como quarta parte do livro El subdesarrollo latinoamericano y la teoria del desarrollo, de Osvaldo Sunkel e Pedro Paz; e La história económica del Chile entre 1830 y 1930: dos ensayos e una bibliografia, publicado em 1982 por Carmen Cariola Sutter e Osvaldo Sunkel.

Apesar do aspecto histórico estar presente em todas estas obras e de constituir elemento fundamental do enfoque cepalino, não se pode perder de vista a qualificação muito pertinente feita por Celso Furtado: a distinção entre história econômica e análise do processo econômico no passado. Como se poderá notar mais adiante, esta distinção é oportuna, a princípio, por dois motivos. Em primeiro lugar, para clarificar o papel que a História cumpre no modo de pensamento cepalino e, em segundo lugar, o correto sentido que deve ser atribuído aos ensaios cepalinos de interpretação histórica.

Celso Furtado na Introdução ao seu livro Formação Econômica do Brasil anteviu muito claramente como deveria ser considerado o seu esboço do "processo histórico da formação da economia brasileira". Era "... simplesmente a análise de processos econômicos e não a reconstituição dos eventos históricos que estão por trás desses processos". ${ }^{32}$ Noutras palavras, e seguindo a tradição inaugurada por Prebisch, ele buscou testar as teorias do desenvolvimento aplicando-as aos processos históricos de modo que, neste procedimento, contestasse tais teorias a partir das especificidades do subdesenvolvimento e pudesse, a partir da própria realidade latino-americana, elaborar uma teoria do desenvolvimento compatível com tal realidade.

No prefácio à primeira edição de La economía argentina, Aldo Ferrer deixa transparecer o sentido que a História adquire no modo de pensamento cepalino. Diz ele,

cerca de dos décadas de trabajo en los problemas del país, tanto en plano académico como en la función de gobierno, me han convencido de que el enfoque histórico es el único que permite un comprensión sistemática y global de los problemas del desarrollo nacional $y$, consecuentemente, la formulación de una política de fortalecimiento de la estructura económica, de aceleración del ritmo de desarrollo y de

32 FURTADO, Celso. Formação Econômica do Brasil. 32ª Ed. São Paulo: Companhia Editora Nacional, 2003 [1959], p.7. 
O enfoque histórico-estrutural e a crítica relegada

elevación de nivel de vida de las mayorías del país. ${ }^{33}$

E, na Introdução, Ferrer, reportando-se a Celso Furtado, verbaliza a utilidade do enfoque histórico-estrutural:

La definición de etapas o, si se quiere, de modelos, permite al economista aplicar al conjunto de datos y de estimaciones básicas de que dispone el instrumental analítico moderno, para describir el proceso de desarrollo en términos inteligibles para el lector contemporáneo. Por otro lado, este tipo de enfoque tiene la inestimable ventaja de penetrar en profundidad en el análisis de las causas de la situación presente y de ver cómo estas se fueron desenvolviendo, con el correr del tiempo, hasta llegar a la actualidad. (...) Finalmente, este método obliga al economista a considerar el comportamiento de las fuerzas sociales en el proceso de desarrollo. Esta dimensión suele quedar fuera del campo de problemas que el economista aborda $y$, sin embargo, es indispensable incorporar para interpretar correctamente la formación de una economía. ${ }^{34}$

Sem pretender escrever a história econômica e social da América Latina $^{35}$, Sunkel e Paz ressaltam a importância da interpretação da História latino-americana:

De cualquier manera, se estima que este ensayo ayuda a comprender y sugiere posibles explicaciones de algunos fenómenos y tendencias importantes y persistentes; permite entender la unidad básica que caracteriza la historia socioeconómica y política de América Latina, y a la vez comprender la diversidad de tipos y procesos que se dan dentro de ese marco común; apunta hacia la necesidad de interpretar el proceso del subdesarrollo latino americano como una parte del proceso universal de formación de las relaciones económicas internacionales; insinúa posibilidades ciertas para el trabajo multidisciplinario y convergente de economistas,

33 FERRER, Aldo. La Economía Argentina: desde sus orígenes hasta principios del siglo XXI. $3^{\mathrm{a}}$ ed. Buenos Aires: Fondo de Cultura Económica, 2004 [1 963], p. I3-4, negrito nosso.

34 FERRER, A. ibid., p. I5, negrito nosso.

35 "Es importante subrayar, (...), que no se trata aquí de escribir la histórica económica y social de América Latina; antes bien, se pretende interpretala, recurriendo a un enfoque global y al arsenal de las ciencias sociales" SUNKEL, O. \& PAZ, P. op.cit., 1970, p.27I. 
sociólogos, especialista en ciencia política, historiadores y otros cientificos sociales; abre plurales y promisores rumbos de investigación tanto de tipo general como concretos y especificos; y sobre todo, puestos que es el propósito de esta investigación, ayuda a pensar en términos de formulación estrategias de desarrollo. ${ }^{36}$

Entre tantas vantagens não se pode deixar perder a lembrança dos limites do enfoque histórico-estrutural. Isto implica posicionar a História nos diferentes momentos da reflexão. No modo de pensamento cepalino, ao que tudo indica, a reflexão teórica precedeu a reflexão histórica. Precedeu no sentido de que os autores cepalinos buscavam testar as hipóteses explicativas das teorias convencionais do desenvolvimento em realidades pretéritas (situações históricas particulares) de modo a desaprová-las ou não por meio das características particulares da realidade latino-americana. Não se tratava necessariamente de refutar os esquemas analíticos por completo e sim discutir se os padrões de interação entre as variáveis de tais esquemas deveriam ser tomados como modelo para o desenho de políticas de desenvolvimento.

Na Introdução ao livro Teoria e Política do Desenvolvimento Econômico, Celso Furtado expõe esta questão: "a necessidade de diagnosticar a problemática de sistemas econômicos nacionais, em fases diversas de subdesenvolvimento, levou [o autor] a aproximar a análise econômica do método histórico". ${ }^{37}$ Furtado ainda indica o "lugar" da História no momento da reflexão,

O estudo comparativo de problemas similares no plano abstrato, em variantes condicionadas por situações históricas diversas e em distintos contextos nacionais, induziu [o autor] progressivamente a adotar um enfoque estrutural dos problemas econômicos. É sua opinião que o esforço mais necessário, no plano teórico, a ser realizado na fase atual, consiste na identificação progressiva do que é específico de cada estrutura, como base para a elaboração de uma tipologia das estruturas. ${ }^{38}$

36 SUNKEL, O. \& PAZ, P. op.cit., 1970, p.272.

${ }^{37}$ Furtado, Celso. Teoria e Política do Desenvolvimento Econômico. São Paulo: Companhia Editora Nacional, 1967 [1961] p,XIV e XV.

${ }^{38}$ Furtado, C. op.cit., 1967, p.XV. 
Note-se que o uso crítico da teoria levou, portanto, ao estudo da História, não o contrário. Da justaposição da teoria em diferentes períodos da História surgiu a possibilidade de elaborar tipologias das diferentes estruturas que compunham a realidade latino-americana, auxiliando, deste modo, a reflexão do fenômeno do subdesenvolvimento. Sem embargo, tal procedimento pode ser interpretado como um esforço para estabelecer os limites históricos nos quais as teorias do desenvolvimento teriam significado. Tratava-se, pois, de historizar as leis econômicas. Neste caso, a História é o particular. É também princípio de variação/distinção das economias. E, ainda, a justificativa epistemológica para a crítica e o avanço em relação às teorias questionadas.

Uma vez apresentados os dois elementos do enfoque histórico-estrutural, expõe-se agora como foi processada analiticamente a realidade latino-americana (seção e) e como se formou a partir dela uma visão do processo histórico (seção f).

\section{Encadeamento lógico no enfoque histórico-estrutural}

A realidade latino-americana nunca foi homogênea. Admitia-se, destarte, que uma teoria do subdesenvolvimento deveria necessariamente contemplar tanto as características comuns como as especificidades de cada caso latino-americano. Na reflexão cepalina, por exemplo, o modelo de desenvolvimento hacia afuera e o modelo de substituição de importações podem ser considerados arquétipos explicativos que buscam exprimir o modo através do qual as diferentes realidades da América Latina se desenvolveram nos diferentes momentos da História do continente. Estes modelos foram concebidos levando em consideração os conceitos pré-analíticos (a noção centro-periferia), como apresentados anteriormente, o vínculo entre o crescimento econômico e a expansão do setor exportador. Embora os diferentes casos pudessem ser explicados por estes modelos "gerais", concretamente foi necessário elaborar tipologias que exprimissem as especificidades de cada caso, o que se fez partindo da premissa segundo a qual a formação econômica da América Latina deveria ser concebida como resultado do efeito da expansão do capitalismo comercial sobre uma situação histórica, econômica e social pré-existente. Sob esta premissa, a 
capacidade de diversificação do setor exportador foi eleita como categoria analítica fundamental, pois, segundo se pensava, esta categoria refletia bem a relação entre as economias latino-americanas e o mercado mundial, pelo menos até a Crise do Antigo Sistema Colonial no final do século XVIII. O impacto da expansão do capitalismo comercial sobre o continente latino-americano nos diferentes momentos de sua História deu origem a três tipos básicos de sociedades, a saber: sociedades de agricultura excedente, sociedades de agricultura de subsistência e regiões abundantes em recursos naturais e escassa população (áreas vazias). ${ }^{39}$

Uma vez encontrada uma certa coerência (estabilidade dos vínculos através do tempo) entre as diferentes estruturas que compõem cada realidade da América Latina, a hipótese do impacto externo, que desencadeia novamente uma nova redefinição dos vínculos entre as estruturas internas, é sempre recolocada como princípio dinâmico da explicação. Esta hipótese se manifesta, portanto, na capacidade de diversificação do setor exportador que, no enfoque histórico-estrutural, assume papel principal para a compreensão das mudanças qualitativas.

Por exemplo, no modelo de crescimento para fora, se se considerar que o subdesenvolvimento é um aspecto do processo global de desenvolvimento e que este processo mais geral apresenta transformações qualitativas de um momento para outro (e.g., a Revolução Industrial), de que maneira o enfoque cepalino explica a mudança estrutural (o desenvolvimento) e a maneira como ela se processa nas economias subdesenvolvidas? Segundo o pensamento cepalino isto depende de dois elementos, a capacidade de diversificação do setor exportador e da reação interna da economia nacional correspondente. De maneira muito precisa, Sunkel e Paz nos explicam:

La capacidad de diversificación dependerá de una serie de elementos, entre los cuales se indican los siguientes: el periodo en lo cual el sector exportador se encuentra en expansión; la tecnología de actividad exportadora, que determina la forma en que se combinan los factores, la productividad de los insumos y el volumen del excedente; las formas particulares de utilización de los insumos y de los servicios financieros comerciales, de transporte, de energía, de comunicaciones, etc.; las cantida-

39 SUNKEL, O. \& PAZ, P. op.cit., 1970, p.277. 
O enfoque histórico-estrutural e a crítica relegada

des y estructuras de empleo; la distribución del ingreso y las características de la demanda ulterior que ésta genera; la localización y dimensión espacial de la actividad exportadora (enclave petrolero vs. Ganadería extensiva, por ejemplo); y las formas de organizar la producción y los sistemas de propiedad (nacional o extranjera) de la empresa exportadora. ${ }^{40}$

Por outro lado, do ponto de vista da economia nacional,

La reacción interna, a su vez, dependerá de la situación preexistente, la cual es producto del proceso histórico anterior y de la manera en que influye el Estado al tratar de obtener una mayor participación en el excedente generado y el destino que le dará dependerán de la estructura sociopolítica que el Estado representa, de las ideologías y politica que inspiren su acción, de la eficacia y naturaleza del aparato estatal y de las características de la burocracia que lo administra y compone. ${ }^{41}$

Exprimi-se, assim, o encadeamento lógico da seqüência de raciocínios que subjaz a interpretação da realidade pelos cepalinos na primeira fase da instituição.

\section{A interpretação cepalina da história econômica latino-americana}

Se até aqui a presente exposição do modo de pensamento cepalino foi capaz de apresentá-lo em seus traços fundamentais, então já é o momento de demonstrar como o enfoque histórico-estrutural se manifesta num discurso que, embora muitas vezes tomado como narrativa histórica, na essência, deve ser tratado como uma análise dos processos econômicos no passado.

Entre os trabalhos citados, volta-se a atenção para o livro Un Ensayo de Interpretación del Desarrollo Latinoamericano de Osvaldo Sunkel e Pedro Paz, pois o intuito desta seção é tornar evidente como o pensamento cepalino processou, em geral, a leitura da História latino-americana, em especial no que tange aos critérios de periodização.

Um olhar atento sobre o quadro das relações centro-periferia como esboçam Sunkel e Paz, dá-nos uma dimensão ampla dos diferentes períodos

${ }^{40}$ SUNKEL, O. \& PAZ, P. op.cit., 1970, p.9.

4I SUNKEL, O. \& PAZ, P. op.cit., 1970, p.9. 
históricos em que o processo global de desenvolvimento foi apreendido e compreendido pela primeira geração de cepalinos. Por motivos de adequação não se prolongará a discussão descrevendo cada período minuciosamente. Convém, para os fins que se almejam neste ensaio, dar atenção à maneira como se explica a transição de um período a outro a partir do enfoque histórico-estrutural.

Ao longo da leitura do ensaio de Sunkel e Paz, cada momento da evolução da periferia é resultado de um impacto externo. A formação da economia moderna latino-americana seria resultado do impacto da evolução do capitalismo comercial sobre uma estrutura pré-existente (como já vimos anteriormente). Daí decorre a conformação de estruturas econômicas, sociais e políticas coloniais que adquirem características próprias e que estão vinculadas com as estruturas centrais, subordinadas ao capitalismo comercial, pelo sistema mercantilista colonial. Quando os impérios coloniais entram em crise, implicando uma série de mudanças no centro, apresentou-se um conjunto de novas circunstâncias às quais as estruturas coloniais reagiram, levando ao processo de formação dos Estados nacionais na periferia que geraram mudanças qualitativas nas diferentes realidades latino-americanas. Se no marco do período mercantilista o desenvolvimento das economias latino-americanas poderia ser descrito pelo modelo colonial, no marco do período liberal e, mais precisamente, no momento de apogeu da Revolução industrial no centro, o modelo de crescimento hacia afuera era o que melhor descrevia as estruturas internas das economias latino-americanas e o forma como estas se vinculavam com as economias centrais. Com a crise do liberalismo novamente se constitui um conjunto de circunstâncias externas aos países da América Latina que, por sua vez, se apresentam como desafios e induzem reações internas a partir das quais se organizaram novas estruturas internas com vinculações qualitativamente distintas das etapas anteriores. O novo modo de desenvolver-se que se estruturou no período de crise do liberalismo foi denominado industrialização por substituição de importações. No momento em que foi escrito o livro em exame, tinha-se consciência de que tal modelo já não explicava o que se processava nas economias latino-americanas, muito embora eles ainda não tivessem delimitado qual o padrão de desenvolvimento que se gestava na expansão do capitalismo durante o pós-guerra. 


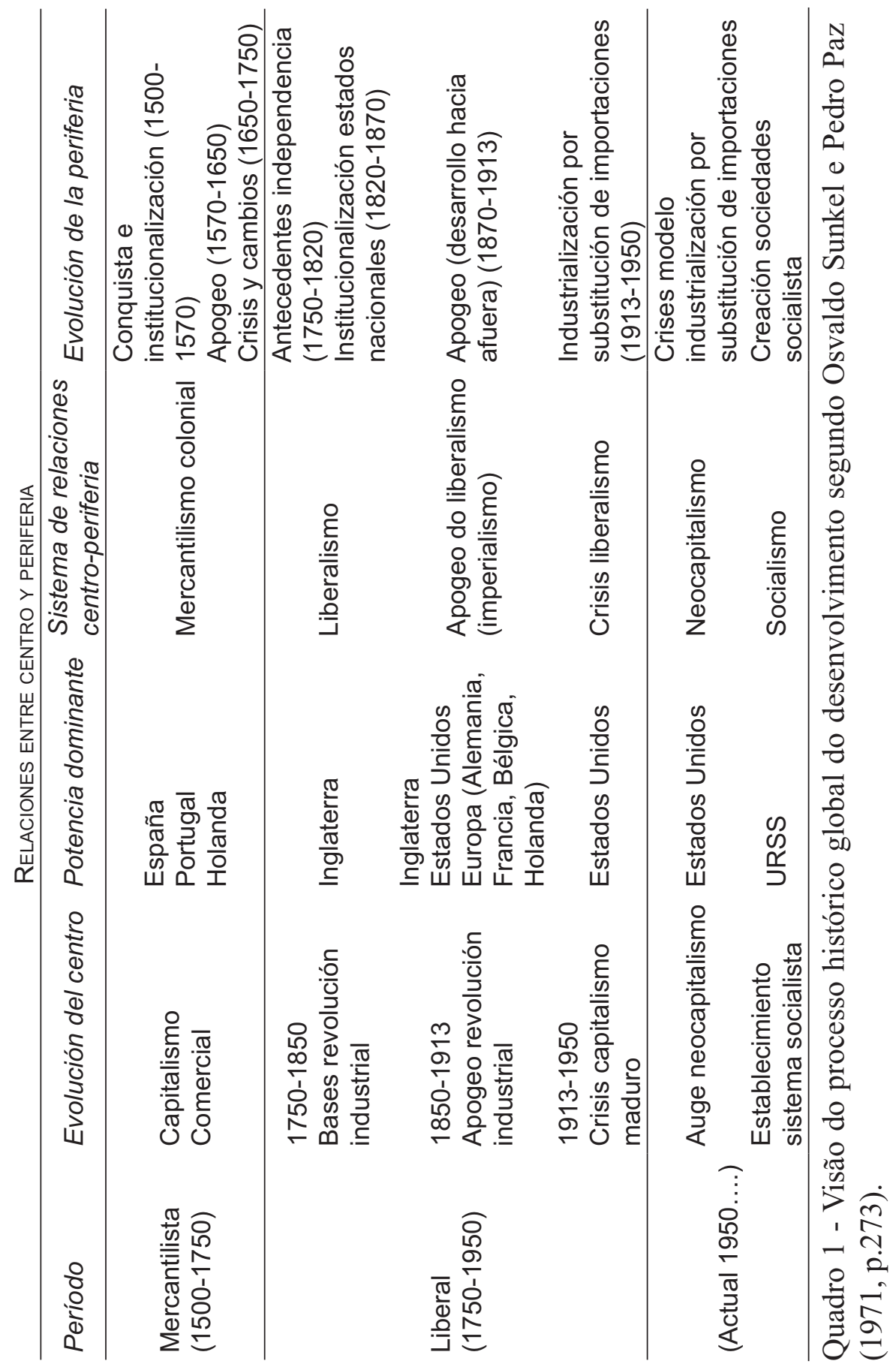


Portanto, que a elaboração dos modelos explicativos formulados pela Cepal para explicar o desenvolvimento econômico latino-americano seguiu em geral o seguinte procedimento: admitiu-se, em primeiro lugar, que o desenvolvimento é um processo global conformado por um conjunto de estruturas desenvolvidas e subdesenvolvidas que juntas formam um único sistema; em segundo lugar, tomou-se um ponto de referência, a América Latina, considerada como periferia; em terceiro lugar, do ponto de vista da periferia, reconheceu-se que a realidade latino-americana era produto da tensão entre as estruturas internas e externas. Contudo, embora se tenha admitido que a realidade latino-americana deveria ser concebida como fruto de uma tensão constante entre estruturas, a leitura deixa subentendido que os movimentos internos são antes um reflexo das transformações observadas no centro, i.e., as estruturas econômicas latino-americanas não apresentam dinâmica própria e estão subordinadas à dinâmica da acumulação que se processa no centro do sistema. Daí, portanto, o procedimento de interpretação da realidade latino-americana sempre partir de uma noção de um quadro externo que se transforma e repercute sobre a estrutura interna, a qual, por sua vez, reage àquela.

\section{Entre o ecletismo possível e a (im)possibilidade da crítica epistemológica}

Exposto em que consiste o enfoque histórico-estrutural e como a realidade latino-americana foi interpretada por este procedimento analítico, tece-se, nesta seção, alguns comentários que parecem pertinentes quando se trata de uma reflexão crítica.

A riqueza do método histórico-estruturalista reside, de acordo com Ricardo Bielschowsky ${ }^{42}$, na associação de duas técnicas de investigação: procedimento indutivo com abstração teórica. Por meio da indução os cepalinos buscavam identificar padrões específicos de inserção na economia mundial ao mesmo tempo em que, através de exercício teórico-abstrato (a concepção de centro-periferia), os padrões específicos de inserção intuídos foram considerados determinados por e determinantes de estruturas socioeconômicas particulares. Assim colocada, a problemática do desenvolvimento econômico latino-americano possibilitou o reconhecimento do modo de

42 BIELSCHOWSKY, R. op.cit., 1998. 
ser específico destas economias. A riqueza do método histórico-estrutural reside, pois, no caráter não-determinista do modo de pensamento cepalino.

A simplificação excessiva não é atributo do enfoque histórico-estrutural. Pensar o subdesenvolvimento com o horizonte de transformá-lo exigiu (e exige) que os pensadores cepalinos desenvolvessem um método de análise em que as relações de dominação econômico-sociais não fossem reduzidas teoricamente com base em esquemas explicativos deterministas (e.g. teoria das vantagens comparativas). Nesse sentido, o caráter não-determinista do pensamento cepalino impõe-se com base em três aspectos, quais sejam: (i) o reconhecimento da insuficiência do mercado para induzir transformações estruturais que levem à superação do subdesenvolvimento; (ii) a incapacidade explicativa ordinária da análise estática e mecanicista do sistema econômico quando isolado do seu contexto social e político; e (iii) a crítica à visão segundo a qual seria possível assegurar homogeneidade econômico-social das economias latino-americanas a partir da "eficiência alocativa dos mecanismos de mercado".

Uma vez que a perspectiva da transformação da realidade econômica e social latino-americana foi colocada como um fim imanente à luz da ideologia do progresso, postulou-se o intervencionismo estatal como condição necessária à superação do subdesenvolvimento. ${ }^{43}$ De acordo com Octavio Rodríguez, a insuficiência do mercado como indutor de transformações estruturais exigiu que o Estado se transformasse em ator principal, articulando e racionalizando o processo de desenvolvimento econômico por meio de políticas de desenvolvimento. Ademais, o reconhecimento por parte dos cepalinos de que o sistema econômico se articulava com as

${ }_{43}$ De acordo com SUNKEL, O. \& PAZ, P. op.cit., 1970, p.35-6, "Esta corriente de ideas tuvo probablemente su culminación política en 1961, en la Carta de Punta del Este y en la concepción inicial - y nunca realizada - de la Alianza para el Progreso. En esa ocasión, en efecto, los gobiernos latinoamericanos, dentro de un nuevo esquema de cooperación internacional multilateral con Estados Unidos, expresaron su decisión de impulsar y realizar ese conjunto de políticas, utilizando la planificación como instrumento para plasmarlas en la realidad". Uma espiada no preâmbulo da Carta de Punta del Este, e podemos ter uma noção exata de quais aspirações estavam colocadas naquela época: "Há quase 200 anos se iniciou neste Hemisfério, a longa luta pela liberdade, fonte de inspiração para os povos do mundo. Alentados pela esperança que dimana das revoluções ocorridas nestas jovens nações, muitos homens hoje, batem-se pela liberdade, em terras de antiga tradição. É chegado o momento de imprimir novo sentido a esta vocação revolucionária. Encontra-se a América nos umbrais de nova era histórica. Homens e mulheres de todo o Continente procuraram conquistar a vida mais plena que as técnicas modernas põem ao seu alcance. Estão resolvidos a conseguir uma existência mais digna e cada vez mais abundante, para si e para os seus filhos; a obter acesso à cultura e iguais oportunidades para todos e a eliminar condições que beneficiam a poucos, em detrimento das necessidades e dignidade de muitos" Carta de Punta del Este, disponível na integra em Revista Brasileira de Política Internacional. Ano IV, No. 16, Dezembro de I96I, pp. I57-I69. 
diferentes esferas da existência social reforçou o papel do Estado como articulador na medida em que o processo de superação do subdesenvolvimento econômico requeria uma base de sustentação política que organizasse e conciliasse relações sociopolíticas e geopolíticas. Por fim, “... admitir un 'no determinismo' legitima la búsqueda de alternativas para los procesos globales de desarrollo, que contemplen la compatibilidad de los elementos mencionados, y con ella, la continuidad de tales procesos, en los marcos de la(s) alternativa(s) elegida(s)" ${ }^{44}$.

Com base nesses elementos, pode-se considerar a orientação de pesquisa histórico-estrutural como método? Rigorosamente, não. Considerar a perspectiva analítica cepalina como enfoque histórico-estrutural, parece ser mais adequado. A noção de enfoque requer menos precisão epistemológica e dá maior liberdade ao desenvolvimento reflexivo. Trata-se, em verdade, de um esforço analítico eclético que acomoda a história econômica e a econometria retrospectiva. ${ }^{45}$ Deste modo, o enfoque histórico-estrutural se apresenta como um modo peculiar de problematizar o desenvolvimento econômico em que as preocupações de cunho epistemológico foram relegadas quando não deixadas à própria sorte.

Não se trata apenas de uma questão semântica e sim de reconhecer o discurso enquanto prática política no plano da ideologia. O status de método requereria exatidão e clareza epistemológica, e não parece ter sido este o caso do pensamento cepalino. Como certa vez comentou Maria da Conceição Tavares, "todo mundo sabe que no Brasil todos os grandes formadores de 'Escola' não têm método nenhum! São todos ecléticos, todos! Ora, qual é o método?"46

Neste momento da argumentação, é oportuna a seguinte observação de Octavio Rodríguez: "el estructuralismo latinoamericano no pretendió sustentarse en fundamento epistemológico preciso, limitándose a establecer ciertos requisitos de método implicados en el estudio del subdesarrollo o bien de la 'condición periférica"'47. O enfoque histórico-estrutural, ao pro-

44 RODRÍGUEZ, O. op.cit, 2006, p.31-32.

45 Para uma distinção entre história econômica e econometria retrospectiva ver MARIUTTI, Eduardo Barros. Colonialismo, Imperialismo e o Desenvolvimento Econômico Europeu. São Paulo: Aderaldo \& Rothschild, 2009, em particular pp.28-34.

46 TAVARES, Maria da Conceição. In: Conversa com economistas brasileiros. BIDERMAN, L.F.L.C. \& REGO, J. M. (orgs.). São Paulo: Editora 34, 1996, p. 133.

47 RODRÍGUEZ, O. op.cit, 2006, p.35-36. 
por um pensamento crítico a partir da combinação de raciocínio indutivo e ponderações históricas, só pode ser considerado método enquanto este não for distinto de doutrina. Neste sentido, seria uma doutrina latino-americana que surge contra o liberalismo econômico reinante.

A partir do enfoque histórico-estrutural foi possível demonstrar, portanto, pelo caráter não-determinista do desenvolvimento econômico. Com isso, introduziu-se no horizonte de expectativa das sociedades latino-americanas não só a existência de diferentes opções ou vias de desenvolvimento, mas a possibilidade da construção do seu devir histórico, em que o Estado passava a assumir papel central enquanto sujeito transformador.

A denominação método, que é muitas vezes utilizada e que imprime caráter "científico" ao pensamento cepalino, mais complica do que ajuda a compreender a contribuição deste pensamento enquanto crítica do real e postulação do "dever ser".

\section{A CONTRIBUIÇÃO DA PERSPECTIVA DOS SISTEMAS- -MUNDO}

Encaminhando-se para derradeira etapa da presente reflexão, como se poderá observar em outra oportunidade, este modo cepalino de interpretar a realidade latino-americana sofreu fortes críticas, tanto internas como externas, na ocasião da crise econômica que tocou o continente latino-americano com o esgotamento do modelo de substituições de importações, concomitantemente à crise política que levou a instauração de ditaduras militares no continente.

Naquele contexto, tiveram lugar, externas à Cepal, as incisivas críticas oriundas do marxismo revolucionário latino-americano, como os trabalhos de Ruy Mauro Marini, Theotonio dos Santos e Vânia Bambirra. Por outro lado, entre as críticas provenientes de autores herdeiros da "tradição" cepalina, nem por isto menos contundentes, destacam-se os clássicos textos: de Fernando Henrique Cardoso e Enzo Faletto, Dependência e Desenvolvimento na América Latina, de 1969; e O Capitalismo Tardio, de João Manuel Cardoso de Mello. Apesar de todas estas diferentes revisões criticarem certos aspectos do modo de pensamento cepalino àquela época, delas surgiram novas correntes do pensamento social latino-americano, que sugeriram 
novas interpretações a respeito do subdesenvolvimento latino-americano e propuseram diferentes programas de ação política.

O projeto consiste em seguir a reflexão que vem sendo desenvolvida sobre os modos de pensamento e as narrativas históricas que se conformaram a partir dos diferentes enfoques sugeridos. Como já foi apontado na introdução do presente trabalho, este é um caminho necessário a ser percorrido, sobretudo para aqueles que pretendem esboçar novas narrativas históricas que contemplem o Brasil na formação e desenvolvimento do Capitalismo. Se tal sugestão não estiver equivocada, a superação crítica dos diferentes modelos explicativos deverá partir das divergências internas e externas ao modo de pensamento de cada interpretação. Entende-se, doravante, que este trabalho de revisão deve ser realizado sob o véu de uma nova concepção de ciência social ainda em formação que se propõe a pensar os desafios postos pela realidade no atual momento de crise do sistema-mundo moderno.

Nesta direção a Perspectiva dos Sistemas-Mundo se coloca como uma referência fundamental, pois, ela proporciona hoje bases sólidas, embora não totalmente desenvolvidas, que podem ajudar a pensar o Brasil na formação e desenvolvimento do Capitalismo, bem como, em compreendendo o Brasil, aprofundar nossos conhecimentos sobre o Capitalismo. ${ }^{48}$ Por um lado, esta perspectiva propõe o conceito de sistema-mundo moderno enquanto estrutura significativa na qual as diferentes trajetórias de desenvolvimento no mundo moderno ganham sentido, constituindo-se numa unidade contraditória, i.e, numa totalidade. Por outro lado, resgata e coloca à disposição

\footnotetext{
${ }^{48}$ No Brasil alguns esforços têm sido realizados com o intuito de pensar o Brasil à luz da Perspectiva dos Sistemas-Mundo. Entre os trabalhos que apresentam a Perspectiva destacam-se: MARIUTTI, Eduardo Barros. "Considerações sobre a perspectiva do sistema-mundo". Novos Estudos, CEBRAP, n.69, julho, 2004; e ARIENTE, Wagner Leal; FILOMENO, Felipe Amin. "Economia politica do moderno sistema mundial: as contribuições de Wallerstein, Braudel e Arrighi". In: Ensaios FEE, Porto Alegre, v. 28, n. I, p. 99- I26, jul. 2007. Entre os trabalhos que se inspiram nela para repensar questões na historiografia econômica brasileira destacam-se: FILOMENO, Felipe Amin; VIEIRA, Pedro Antonio. "Impacto da transição da hegemonia financeira mundial do Reino Unido para os EUA sobre a política econômica brasileira e argentina nos anos 1920". In: História Econômica e História de Empresas. Vol. X.2, 2007, pp. I05- I38; FILOMENO, Felipe Amin. "A crise Baring e a crise do Encilhamento nos quadros da economia-mundo capitalista". In: Economia e Sociedade, Campinas, vol. 19, n. I (38), pp. I35- I7I, abr. 20 I 0; VIEIRA, Pedro Antonio. "A inserção do 'Brasil' nos quadros da economia-mundo capitalista no período I550-c. I800: uma tentativa de demonstração empírica através da cadeia mercantil do açúcar". In: Economia e Sociedade, Campinas, vol. 19, n . 3 (40), pp.499-527, dez. 20 I 0. Entre os trabalhos que procuram revisar modelos explicativos do desenvolvimento latino-americano destacam-se: VIEIRA, Pedro Antonio. VIEIRA, P. A. "Um crítica ao conceito de dependência a partir do conceito de economia-mundo". Cadernos de Economia (UNOESC), Chapecó, v. I 5, 2004; PRADO, Fernando Correa. Impensar el Desarrollo en América Latina: elementos para la crítica al neodesarrollismo actual a partir de la teoría marxista de la dependencia y el análisis de sistemas-mundo. (Dissertação de Mestrado), UNAM, 2010.
} 
do pesquisador o recurso da comparação como estratégia de pesquisa para conceber a mudança social no moderno sistema-mundo.

Se a reflexão cepalina, ao rebelar-se contra o universalismo evocado desde o centro, expressava o desconforto que as verdades tradicionais causavam na periferia do sistema-mundo moderno nas décadas de $1950 \mathrm{e}$ 1960, mesmo tendo encontrado, num determinado momento, a rationale do processo de industrialização, o modo de pensamento cepalino não enfrentou as questões epistemológicas colocadas pela tarefa de teorizar o subdesenvolvimento. Se historicamente, do ponto de vista da luta econômica e política, a Cepal se colocou em princípio contra o liberalismo econômico dominante, esta luta se refletiu, na esfera do conhecimento, no confronto contra o universalismo europeu, muito embora, despida de uma crítica epistemológica.

A Perspectiva dos Sistemas-Mundo, por sua vez, nasceu como uma crítica epistemológica às estruturas do saber da economia-mundo capitalista. ${ }^{49}$ É esta crítica que deve ser considerada nos esforços de revisão crítica dos modelos explicativos da História econômica latino-americana, em particular, da História econômica do Brasil.

A modalidade de pensamento sugerida pela Perspectiva dos Sistemas-Mundo fornece um instrumental analítico que viabiliza efetivamente a reflexão totalizante articulando as diferentes esferas da existência social ao mesmo tempo em que cultiva em nós uma postura herege, desafiadora, de questionamento dos conceitos ou noções com as quais o sujeito do processo do conhecimento está acostumado a pensar, como, por exemplo, a dualidade interno-externo, ou o princípio hierarquizante em primeira instância e em última instância, e, principalmente, o dilema excludente entre o conhecimento idiográfico e o conhecimento nomotético. Não se pretende com esta observação negar a existência de determinações, nem negar a ne-

\footnotetext{
49 Como certa vez pontuou Wallerstein (1999, p.447), a "análise dos sistemas mundiais" não é uma teoria sobre o mundo social, nem sobre uma parte dele. É um protesto contra os modos pelos quais a investigação científica social foi estruturada para todos nós desde o seu início em meados do século XIX. Este modo de investigação tornou-se um conjunto de pressupostos a priori quase sempre não-questionados. A análise dos sistemas mundiais sustenta que esse modo de investigação científica social, praticada em todo o mundo, teve o efeito antes de fechar do que abrir muitas das mais importantes ou mais interessantes questões. Ao usar os antolhos que século XIX construiu, somos incapazes de cumprir a tarefa social que desejamos cumprir e que o resto do mundo deseja que cumpramos, que consiste em apresentar racionalmente as alternativas históricas que estão diante de nós. A análise dos sistemas mundiais nasceu como protesto moral e, em seu sentido mais amplo, político. No entanto, é com base nas asserções científicas, vale dizer, com base nas asserções relacionadas com as possibilidades de conhecimento sistemático acerca da realidade social, que a análise dos sistemas mundiais desafia os modos de investigação predominantes".
} 
cessidade de reconhecê-las no real. Sugere-se apenas que tanto o princípio de ordenação (primeira e última instância) como o princípio de constituição (interno-externo) devem ser considerados a partir do fenômeno em análise, inscrito na estrutura significativa na qual este ganha sentido. Do contrário, ambos os princípios perdem validade, enquanto recursos analíticos, numa falsa totalidade ${ }^{50}$. Portanto, a revisão dos modelos explicativos da História latino-america requer também uma revisão da unidade de análise a partir da qual o desenvolvimento capitalista foi historicamente estudado.

\section{CONSIDERAÇÕES FINAIS}

Percorreu-se um longo caminho até aqui. Chamou-se a atenção para necessidade atual de revisar criticamente as interpretações da formação e desenvolvimento do capitalismo na América Latina. Em seguida, cuidadosamente, enveredou-se pelo pensamento originário da Cepal em busca de um esboço de caracterização de seu modo de pensamento. Com tal intuito, foram apresentadas algumas visões acerca do que representaram historicamente, do ponto de vista do conhecimento, as idéias fundadoras da Cepal. Caracterizou-se, deste modo, o enfoque histórico-estrutural como um modo peculiar de pensamento e, como tal, argumentou-se que este, em sua essência, consistiu numa contraposição ao princípio universalista subjacente às teorias convencionais do desenvolvimento. Demonstrou-se também que tal empresa esteve apoiada em conceitos pré-analíticos (estrutura, sistema e processo) a partir dos quais a noção centro-periferia expressava, no plano das modernas estruturas do saber, a luta pelo desenvolvimento das sociedades de passado colonial.

Apontou-se que esta batalha foi travada através da historização das "leis" econômicas. Conseqüentemente, indicou-se que as narrativas históricas cepalinas não se confundem com a disciplina história econômica, senão

\footnotetext{
50 A falsa totalização deriva dos métodos de princípios abstratos que atribuem sentido ao real de acordo com a lógica previamente definida pela própria teoria. Nestes casos, a diversidade do real é perdida pelo motivo dos juízos a priori valoram os fatos apenas no contexto da teoria. Portanto, de acordo com Kosík (1969, p.49 grifo do autor), "o método do 'princípio abstrato' deforma a imagem total da realidade (acontecimento histórico, obras de arte) e ao mesmo tempo se mostra destituído de sensibilidade em face dos particulares. Está a par dos fatos (particulares) mas o obscurece". O autor ainda continua, "assim fazendo rompe a integridade do fenômeno em causa porque o cinde em duas esferas independentes: uma parte que convém ao princípio e que por ele é explicada; e uma outra parte que contradiz o princípio e que, portanto, permanece na sombra (sem explicação e compreensão racional), com 'resíduo' não explicado e inexplicável do fenômeno".
} 
que se constituem como análises de processos econômicos no passado. Foi nesta operação que se chamou a atenção para o fato da crítica epistemológica ter sido relegada e da necessidade de ser retomada atualmente. Tal crítica tem sido um dos pilares da Perspectiva dos Sistemas-Mundo e, como tal, foi argumentado que esta pode lançar novas luzes no debate sobre o desenvolvimento neste momento de crise do sistema-mundo moderno. A revisão dos modelos explicativos é um longo caminho a ser percorrido que, lentamente, está se adensando.

\section{HISTORICAL-STRUCTURAL APPROACH AND A NEW CRI- TIQUE}

\section{Abstract}

This paper aims, on the one hand, to review the ECLAC's thought, focusing on constitutive aspects of its way of thinking, and their implication to formulation of narratives about the formation and development of LatinAmericans economies; on the other hand, to argue that World-System Perspective might contribute, from their epistemological critique, to a critical review of explicative frameworks of Latin-American development.

Keywords: Eclac, World-System, Latin America.

JEL Classification: NO1; O54.

\section{REFERÊNCIAS}

BIELSCHOWSKY, Ricardo. Cinqüenta Anos de Pensamento da CEPAL Uma Resenha. In: BIELSCHOWSKY, R. Cinqüenta anos de pensamento na Cepal. Vol.1 Rio de Janeiro: Record, 1998;

FERRER, Aldo. La Economía Argentina: desde sus orígenes hasta principios del siglo XXI. $3^{\mathrm{a}}$ ed. Buenos Aires: Fondo de Cultura Económica, 2004 [1963]. 
FURTADO, Celso. Formação Econômica do Brasil. 32a Ed. São Paulo: Companhia Editora Nacional, 2003 [1959].

FURTADO, Celso. Teoria e Política do Desenvolvimento Econômico. São Paulo: Companhia Editora Nacional, 1967 [1961].

GOLDMANN, Lucien. Dialética e cultura. Rio de Janeiro: Paz e Terra, 1967.

GROSFOGUEL, Ramón. A TimeSpace Perspective on Development: recasting Latin America De-bates. In: Review, XX, 3/4, Summer/Fall, 1997.

KOSÍK, Karel. Dialética do Concreto. Rio de Janeiro: Paz e Terra, 1969 [1963].

MARINI, Ruy Mauro. La crisis del desarrollismo. Arquivo de Ruy Mauro Marini, com a anotação "(1994)". Disponível em: $<<$ http://www.marini-escritos.unam.mx/026_crisis_desarrollismo_es.htm $>>$.

MARX, Karl. Contribuição à crítica da Economia Política. 2a Ed. São Paulo: Expressão Popular, 2008 [1859].

MELLO, João Manuel Cardoso de. O Capitalismo Tardio: contribuição à revisão crítica da formação e do desenvolvimento da economia brasileira. $3^{\text {a }}$ Ed. São Paulo: Brasiliense, 1984 [tese de doutorado defendida em 1975 na Universidade Estadual de Campinas].

NOVAIS, Fernando A. Anotações sobe a vida cultural na época do Antigo Regime. In: NOVAIS, F. A. Aproximações: estudos de história e historiografia. São Paulo: Cosac Naify, 2005.

PREBISCH, Raúl. El desarrollo económico de América Latina y algunos de sus principales problemas. In: Desarrollo Económico, Vol. 26, No. 103. (Oct. - Dec., 1986), pp. 479-502. [1949]. 
RODRÍGUEZ, Octavio. El Estructuralismo Latinoamericano. México, Siglo XXI Editores : Cepal, 2006.

RODRÍGUEZ, Octavio. La teoría del subdesarrollo de la CEPAL. México, Siglo XXI Editores, 1980.

SUNKEL, Osvaldo \& PAZ, Pedro. El subdesarrollo latinoamericano y la teoría del desarrollo. $1^{\mathrm{a}}$ ed. México, DF: Siglo Veintiuno, 1970.

WALLERSTEIN, Immanuel. A Análise dos Sistemas Mundiais. In: Giddens, A. e Turner, J. (orgs.). Teoria Social Hoje. São Paulo: Ed. Unesp, 1999, pp.447-470.

WALLERSTEIN, Immanuel. O capitalismo histórico. São Paulo: Brasiliense, 1985.

WALLERSTEIN, Immanuel. O Universalismo Europeu: a retórica do poder. São Paulo: Boitempo, 2007.

WALLERSTEIN, Immanuel. World-System Analysis: an introduction. Durham: Duke University Press, 2004.

Artigo submetido em março de 2011 e aceito para publicação em junho de 2011. 